Bull. Egypt. Soc. Physiol. Sci. 39(2), 143 -157

\author{
Bull. of Egyp. Soc. Physiol. Sci. \\ (Official Journal of Egyptian Society for Physiological Sciences) \\ (pISSN: 1110-0842; eISSN: 2356-9514)
}

\title{
Anti-adiposity impact of phosphodiesterase-5 inhibitor, Sildenafil is possibly through browning of white adipose tissue and FGF21 in obese rats.
}

\author{
Marwa H. Muhammad ${ }^{1}$; Sania K. Elwia ${ }^{2}$; Shaymaa M. Abd El Rahman ${ }^{2}$
}

Department of Medical Physiology ${ }^{1}$, Faculty of Medicine, Benha University, Qalubyia, Egypt ${ }^{1}$, Department of Medical Biochemistry \& Molecular Biology, Faculty of Medicine, Benha University, Qalubyia, Egypt ${ }^{2}$

Received: 19 Dec 2018 Accepted: 19 Mar 2019

Available online: 23 April 2019

\section{Keywords}

- WAT-browning

- Phosphodiesteras e-5 inhibitor

- Pre-existing obesity

- FGF21

- Insulin resistance

\begin{abstract}
Background \& Aim: Fibroblast growth factor 21 (FGF21) is a peptide hormone recently discovered to be released from brown adipocytes. It plays an outstanding role in the metabolic homeostasis. Induction of brown-like adipocytes termed beige/brite within the white adipose tissue (WAT) by means of browning agents is known as "browning process". These beige/brite cells due to plenty of mitochondria and unique expression of uncoupling protein-1 (UCP1), promotes energy expenditure. Being the WAT is excessively expanded in adiposity, the browning agents have gained great interest to combat obesity. The browning effect of Sildenafil (Sild) in obese rats stills a matter of debate. So, we aimed to illustrate it. Method \& Results: 3 groups of rats were conducted; control group fed standard diet for 9 weeks, obese non-treated group fed high-fat diet (HFD)-fed group for 9 weeks, and Sild-treated group fed HFD for 9 weeks and received Sild (20 mg $/ \mathrm{kg} / \mathrm{s}$.c./each) twice daily in the last 3 weeks. Our findings revealed Sild reduced weight gain, fat depots weight, and adiposity index in spite of unchanged food intake. Additionally, it reduced serum triglycerides, free fatty acids, glucose, insulin, and insulin resistance index. The subcutaneous WAT of Sild-treated rats exhibited augmented UCP1, citrate synthase activity, and FGF21 and FGF21Receptor1 expressions with the highest FGF21 serum levels. Conclusions: the present study suggested a protective impact of Sild against adiposity and insulin resistance through browning of WAT with enhanced FGF21-Receptor1 expression.
\end{abstract}

Corresponding author: Marwa Hassan Muhammad. E. Mail: (drmarwahassan448@gmail.com) Mobile: 00201009655692 Address: Department of Medical Physiology, Faculty of Medicine, Benha University, Qalubyia, Egypt. (www.fmed.bu.edu.eg). 


\section{INTRODUCTION}

Obesity stems from an imbalance between energy intake and energy expenditure with abnormal body fat accumulation [1]. Thus, the antiobesity strategies have centred essentially on the decreasing energy intake and/or growing energy expenditure through exercise. However, these behaviour-centred approaches have met only limited achievement in fading the worldwide obesity pandemic [2]. Consequently, there is an urgent need for a safe and effective anti-obesity therapeutics. To validate this, an understanding of the physiological role of the implicated adipose tissue appeared essential.

Body fat exists in two types; white and brown that play opposing roles; white adipose tissue (WAT) is the main energy store while, the brown adipose tissue (BAT) is the main site for energy expenditure. BAT is capable of burning high amounts of fat and glucose, releasing the energy as heat, a function mediated by its unique expression of uncoupling protein 1 (UCP1) within their abundant mitochondria [3]. Moreover, the metabolic activity of the brown adipocytes is much enhanced by the citrate synthase (CS) enzyme which is a unique mitochondrial matrix enzyme that catalyses the first step of the Krebs cycle [4]. BAT's activity has been concomitant with a healthful metabolic profile, which is at least partly due to a sweeper-like action for circulating glucose and lipids, thus preventing extreme fuel deposition, and hence obesity [5].

Fibroblast growth factor-21 (FGF21) is a peptide hormone that was recently discovered to be released from the BAT in addition to its primary organ, the liver [6]. The subcutaneous adipose tissue is an obligatory target for FGF21 [7]. Moreover, the FGF21 exerts pleiotropic biological functions concerning the glucose homeostasis and insulin sensitivity [8]. Thus, the physiological role of BAT to restore energy and metabolic homeostasis may extend beyond its capacity for endorsing energy expenditure to include the production and release of FGF21.

Adult humans possess only petty amounts of BAT; about $0.05 \%$ of the body mass [9]. So, this gives rise to a striking interest in discovering agents that root BAT recruitment through a process called "browning of WAT". It is mediated through induction of the brown-like adipocytes termed beige/brite adipocytes within the WAT. These beige/brite cells have plenty mitochondria and UCP1 as classic brown adipocytes [10]. Thus, these browning agents appeared to deliver a new approach to combat obesity.

The cyclic guanosine monophosphate (cGMP) is an important second messenger in adipocytes. It was discovered to play a crucial role in BAT development and functions [2]. It is specifically hydrolysed by the phosphodiesterase5 (PDE-5) [11]. The Sildenafil (Sild) is a highly selective PDE-5inhibitor [12]. It is commonly available, well tolerated and broadly used for the treatment of erectile dysfunction and pulmonary arterial hypertension [13, 14]. Given its role in raising cGMP, Sild might be an encouraging pharmacotherapy targeting browning of WAT and BAT recruitment as an anti-adiposity approach.

The anti-obesity effects of Sild have been previously studied in lean animals and prediabetic 
and overweight humans [15-17]. However, the available data about its WAT-browning effect stills a matter of debate. Therefore, the present study was designed to investigate the potential impact of Sild on adiposity and the associatedinsulin resistance in obese rats. Browning of WAT and the derived-batokine FGF21 were among the suggested mechanisms.

\section{Materials and method}

\section{Experimental animals}

This study was conducted to 24 adult male albino rats, 6-8 weeks old, and weighing 170 $\pm 10 \mathrm{gm}$. They were purchased from Animal House, Faculty of Veterinary Medicine, Benha University, Egypt. They were housed in metallic cages ( 4 per cage) and maintained on prevailing atmospheric conditions at $23 \pm 1{ }^{\circ} \mathrm{C}$ with free access to food and water.

The present work was carried out in strict respect to the recommendations of the Guide for the Care and Use of Laboratory Animals of the National Institutes of Health. The protocol was revised and approved by the Committee on the Ethics of Animal Experiments of the Faculty of Medicine, Benha University, Egypt.

\section{Drugs and Diets}

Sildenafil (Sild) was isolated from Viagra tablets (Pfizer, Egypt) as previously described by Francis and his colleges [18] and dissolved in $0.9 \%$ saline. The standard and high-fat diets (HFD) were formulated and prepared as pellets at the Faculty of Agriculture, Benha University, Egypt.

\section{Experimental groups and design}

Rats were randomly divided into 3 equal groups ( $n$ $=8$ ). Group I: the control group fed standard diet $(10 \mathrm{kcal} \%$ fat, $20 \mathrm{kcal} \%$ protein, and $70 \mathrm{kcal} \%$ carbohydrate) for 9 weeks. Group II: obese nontreated or HFD group that were fed HFD (45 kcal $\%$ fat, $20 \mathrm{kcal} \%$ protein, and $35 \mathrm{kcal} \%$ carbohydrate) for 9 weeks. Group III: obese Sildtreated group, rats were maintained on the HFD for 9 weeks and received Sild $(20 \mathrm{mg} / \mathrm{kg} / \mathrm{s} . c . /$ each $)$, twice daily in the last 3 weeks. The rats in both Group I and II received an equivalent volume of saline subcutaneously in the last 3 weeks [19].

Body weight and food intake were monitored weekly. The food was weighed before it was given to the animals and again at the same time the next day after removal from the cages. The food consumption was then measured by subtracting the weight of the remaining uneaten food from the supplied. The differences between the weights were divided by the number of rats per cage [20].

At the end of the 9th week, an overnight fasting was allowed and the final body weights were measured. The rats were then anaesthetized by Sodium pentobarbital (40 mg/kg i.p.). The blood samples were obtained by cardiac puncture for serum preparation. The subcutaneous and visceral fat depots were carefully dissected and weighed for calculation of adiposity index. The subcutaneous inguinal WAT fat depot, after weighing, was immediately frozen in liquid nitrogen and stored at $-80{ }^{\circ} \mathrm{C}$ till analysis [21].

The adiposity index was calculated as [Total fat depots weight $(\mathrm{g}) /$ final body weight $(\mathrm{g})] \times 100$ [22], with total body fat was the sum of fat depot weights.

\section{Serum biochemical analysis}

Blood samples were left at room temperature to be clotted then centrifuged at $3000 \mathrm{rpm}$ for $15 \mathrm{~min}$ and the supernatant was obtained and stored at -20 
${ }^{\circ} \mathrm{C}$ till biochemical analysis of serum glucose, insulin, triglycerides (TGs), free fatty acids (FFA), and FGF21 levels.

\section{Determination of serum glucose}

The serum glucose was estimated by the glucose oxidase-peroxidase method, using kits (Cat No; 1001191, Spinreact, Spain). The glucose oxidase enzyme catalyses sample glucose to glucuronic acid. The formed hydrogen peroxide was detected by a chromogenic oxygen acceptor, phenolaminophenazone in the presence of peroxidase, and absorbance was measured at $505 \mathrm{~nm}$.

Measurement of serum insulin was executed using INS-ELIZA kits (MBS 2024649, Biosource, Belgium) and based on the competitive inhibition enzyme immunoassay technique. An antibody specific to insulin has been pre-coated onto a microplate. A competitive inhibition reaction is launched between biotin labeled insulin and unlabelled insulin (standards or samples) with the pre-coated antibody specific to insulin [23].

Calculation of insulin resistance index: Insulin resistance was calculated by homeostatic model assessment-insulin resistance (HOMA-IR) using the following formula: HOMA-IR = fasting blood glucose $(\mathrm{mg} / \mathrm{dl}) \times$ fasting insulin value $(\mu \mathrm{IU} / \mathrm{ml}) /$ 405. A HOMA value more than 2 indicated insulin resistance existence while less than 2 indicates insulin sensitive state [24].

\section{Triglycerides (TGs) and free fatty acids (FFA)} measurement

Serum TGs and FFA levels were measured by enzymatic colorimetric methods using the commercially available kits obtained from
Diamond Diagnostics Company (Cairo, Egypt) by following the manufacturers' instructions.

\section{SerumFGF21 measurement}

Rat FGF21 ELISA Kits (ab223589, Cambridge, UK) were used for assessment of FGF21 protein in the serum. The assay was conducted according to the manufacturer's protocol; the serum samples were diluted 1:3 before the assay and then $100 \mu \mathrm{l}$ diluted sera, calibrators, and quality controls were added to the microtiter plates coated with an affinity-purified polyclonal anti-Rat FGF21 antibody. Finally, a calibration curve was constructed by plotting the absorbance values at $450 \mathrm{~nm}$ versus the FGF21 concentrations of the calibrators, and concentrations of unknown samples were determined by using this calibration curve [25].

\section{WAT citrate synthase (CS) activity assessment}

CS activity Assay kits, (Cat No; CSE1, Detroit R\&D Inc., Michigan, USA) were used to determine CS activity in the frozen subcutaneous WAT homogenate according to the method done by Srere [26]. The CS reaction capacity can be followed by measuring the formation of the - $\mathrm{SH}$ group released from CoA-SH by use of the reactive Ellman reagent (5, 5`-dithiobis [2nitrobenzoic], DTNB) and monitoring the absorbance at $412 \mathrm{~nm}$ [26].

Real-time PCR analysis for UCP1, FGF21, and FGF21-Receptor1 genes in the WAT

RNA extraction, cDNA synthesis and RT-qPCR

A lobule of the stored subcutaneous WAT was homogenized using Mini Kit (Qiagen, USA) according to manufacturer's instruction where the quantity and quality of RNA were evaluated by Nano drop (USA). Total RNA was extracted using 
total RNA purification kit (Jena Bioscience Germany). The concentration and purity of the RNA were determined by measuring the absorbance at $260 \mathrm{~nm}$ and $280 \mathrm{~nm}$ by UV spectrophotometer (Optima SP-3000, Japan). Pure RNA has an A260/A280 ratio of 1.9-2.3.

RNA $(5 \mu \mathrm{g})$ was then reversed transcribed using revert aid TM first strand cDNA synthesis kit (Ferments life science, USA) then cDNA was subsequently amplified with the Syber Green PCR Master Kit (Applied Biosystems, USA)

One-step RT-PCR using QuantiTectVR SYBRVR Green RT-PCR master mix kit Cat No./ID: 204243 (Qiagen, $\mathrm{GmbH}$ ) supplied by clinilab (Egypt), was done in ABI Prism 7900HT (Applied Biosystem, Foster City, CA), QuantiTect SYBR Green RTPCR Kits contain an optimized, ready-to-use master mix using SYBR Green I. QuantiTect SYBR Green RT-PCR master mix also contains dUTP, enabling pretreatment with uracil-Nglycosylase (UNG) prior to starting PCR, which ensures that any contaminating PCR products do not affect subsequent PCR reactions, the prepared reaction components were done in96 well PCR plate using Real-time cycler conditions of $50{ }^{\circ} \mathrm{C}, 30$ min, (Reverse transcription) $95{ }^{\circ} \mathrm{C}, 15 \mathrm{~min}$, (Initial denaturation)followed by 40 cycles of $94{ }^{\circ} \mathrm{C}, 30 \mathrm{~s}$, $55{ }^{\circ} \mathrm{C}, 1 \mathrm{~min}$ and $72{ }^{\circ} \mathrm{C}, 1 \mathrm{~min}$ for Denaturation, Annealing, Extension steps respectively. $\beta$-actin gene was used as an internal control (housekeeping gene).

- Data analysis: According to the RQ manager program ABI prism 7500 the Boxplot software, the data were produced as sigmoid-shaped amplification plots in which the number of cycles is plotted against fluorescence (when using a linear scale). The threshold cycle (CT) served as a tool for calculation of the starting template amount in each sample. Because the relative quantities of the assessed genes are normalized against the relative quantities of the endogenous control $\beta$ actin gene, fold expression changes are calculated using the equation $2^{-\Delta \Delta \mathrm{ct}}[27]$.

Rats' primer sequences of both forward and reverse (Operon, Inc., Huntsville, Alabama, Germany) were as follow:

UCP-1 F: CTCACCTTTGAGCTCCTC and R: CTGATTTGCCTCTGGATG.

FGF21 F: CCTTGAAGCCGGGAGTTATT and R: GGCTTCGGACTGGTAAACAT.

FGF21-R1 F: TGGCACCTGAGGCATTGTT and R: AAGAGCACCCCAAAAGACCAC.

Bactin F: CACCCGCGAGTACAACCTT and R: CCCATACCCACCATCACACC.

\section{Statistical analysis}

All data were analyzed using the program Statistical Package for Social Sciences (SPSS) version 19 (SPSS Inc., Chicago, IL, USA). They are presented as the mean \pm standard deviation (SD). Comparisons of all parameters among the study groups were analyzed by using one-way analysis of variance (ANOVA) test and post hoc multiple comparisons (LSD test). The probability of chance $(P$ value $)<0.05$ was considered statistically significant.

\section{Results}

Effects of HFD and Sild treatment on the body weight, total body fat, adiposity index, and the food consumption (Table 1)

At the end of the experiment, the HFD-fed group showed significant increases in the final body weight, total fat depots weight, and adiposity index 
in comparison to the control group $(\mathrm{P}<0.001)$. On the contrary, The Sild-treated group exhibited significant decreases in the final body weight, total fat depots weight, and adiposity index $(\mathrm{P}<0.001)$ when compared to the HFD-fed group. Regarding food consumption, a significant increase was found in the HFD-fed group with respect to the control group $(\mathrm{P}<0.001)$ while, non-significant change was observed in the Sild-treated group when compared to the HFD-fed group $(\mathrm{P}>0.05)$

Effects of HFD and Sild treatment on the serum glucose, insulin, HOMA-IR, TGs, and FFA parameters (Table 2)

Blood glucose and insulin levels in addition to HOMA-IR index were significantly elevated in HFD-fed rats when compared to the control group $(\mathrm{P}<0.001)$. Conversely, they were significantly reduced in the Sild-treated group when compared to the HFD-fed rats $(\mathrm{P}<0.001)$.

Serum TGs and FFA levels were significantly increased in HFD-fed rats in comparison to the control group $(\mathrm{P}<0.001)$. On the other hand, Sildtreated group exhibited significant decreases in their levels when compared to the HFD-fed group $(\mathrm{P}<0.001)$.

Effects of HFD and Sild treatment on the subcutaneous WAT's UCP1 mRNA expression and CS activity in the experimental groups (Fig 1 and Table 2)

The UCP1 gene expression and CS activity in the subcutaneous WAT were significantly augmented in the Sild-treated group with respect to the other groups $(\mathrm{P}<0.001)$. Moreover, a non-significant change in their levels was observed in the HFDfed rats when compared to the control group (P > $0.05)$.

Effects of HFD and Sild treatment on the FGF21-related parameters in the serum and the subcutaneous WAT of the experimental groups (Fig 1 and Table 2)

Regarding FGF21 mRNA expression in the subcutaneous WAT, a great abundant expression was found in the Sild-treated rats when compared to the other groups $(\mathrm{P}<0.001)$, but a nonsignificant change was observed between the HFD-fed group and the control one $(\mathrm{P}>0.05)$.

The serum FGF21 levels were significantly elevated in the Sild-treated group with respect to the HFD-fed group $(\mathrm{P}<0.001)$. Moreover, it was significantly increased in the HFD-fed group when compared to the control group $(\mathrm{P}<0.05)$.

As regards FGF21-R1 mRNA expression in the subcutaneous WAT, the HFD-fed rats exhibited a highly significant down regulation when compared to the control group $(\mathrm{P}<0.001)$. On the contrary, this receptor expression was significantly upregulated in the Sild-treated group with respect to the other groups $(\mathrm{P}<0.001)$. 


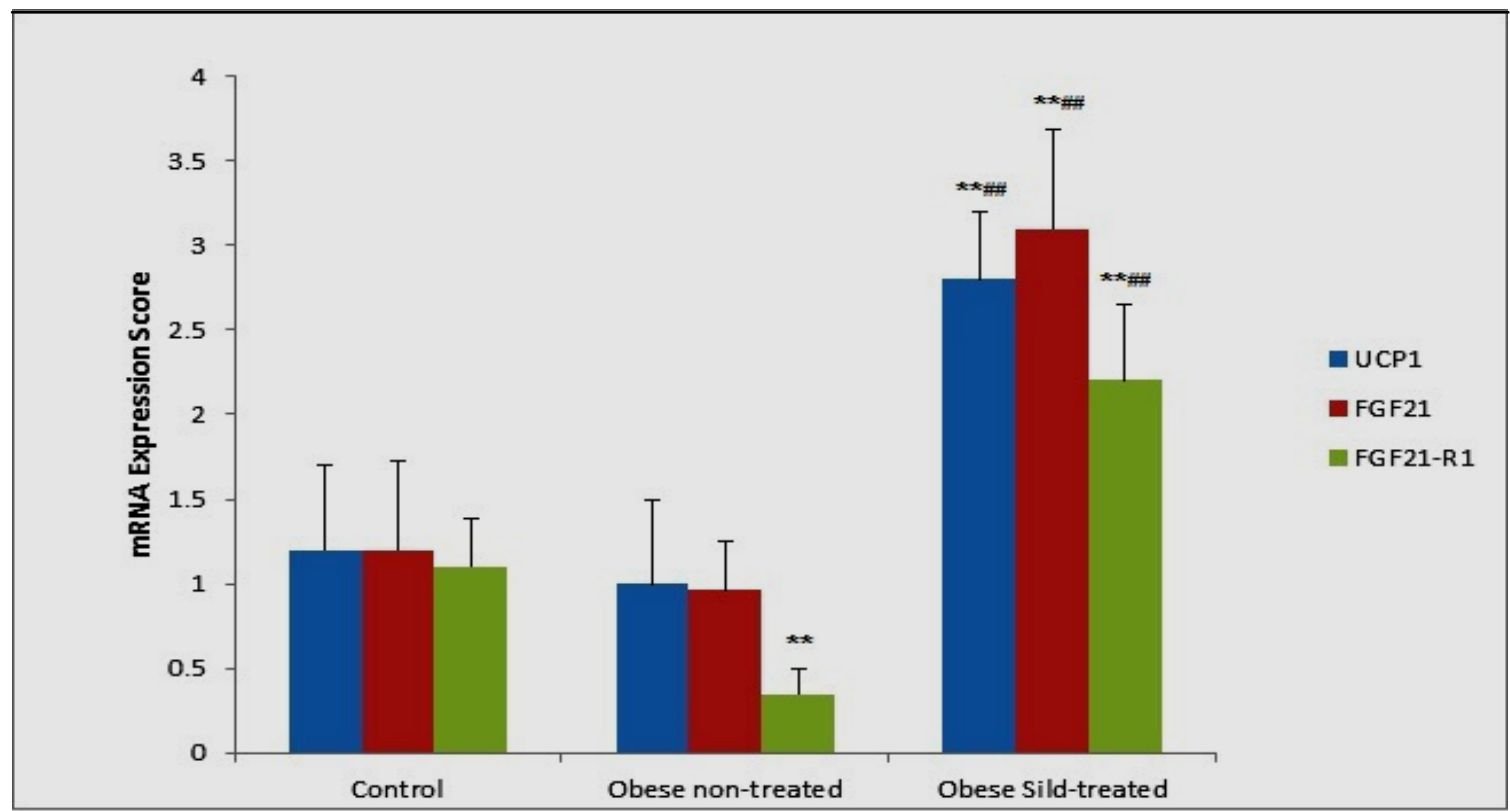

Figure 1 UCP1, FGF21, and FGF21-R1 genes expression in subcutaneous WAT of the experimental groups Data are expressed as mean \pm standard deviation $(\mathrm{SD}) ; \mathrm{n}=8 ; \mathrm{P}$ value $=$ probability of chance, $* \mathrm{P}<0.05$ and $* * \mathrm{P}<0.001$ significant difference compared with the control group while, ${ }^{\#} \mathrm{P}<0.05$ and ${ }^{\# \#} \mathrm{P}<0.001$ significant difference compared with the obese non-treated group. The mRNA expressed by Log10 relative units of relative quantitation. Sild, sildenafil; WAT, white adipose tissue; UCP1, uncoupling protein 1; FGF21, fibroblast growth factor 21; FGF21-R1, fibroblast growth factor 21-receptor 1 .

Table 1 anthropometric parameters of the experimental groups

\begin{tabular}{cccc}
\hline & Control group & Obese non-treated group & Obese Sild-treated group \\
\hline Initial body weight $(\mathbf{g})$ & $170 \pm 10$ & $170 \pm 10$ & $170 \pm 10$ \\
Final body weight $(\mathbf{g})$ & $425 \pm 31$ & $588 \pm 47^{* *}$ & $388 \pm 30^{\# \#}$ \\
Total fat depots weight $(\mathbf{g})$ & $20 \pm 2$ & $64 \pm 5^{* *}$ & $26 \pm 6^{* * \#}$ \\
Adiposity index $(\boldsymbol{\%})$ & $4.8 \pm 0.68$ & $11.1 \pm 0.99^{* *}$ & $6.8 \pm 1.8^{* * \#}$ \\
Food consumption (g/d) & $19 \pm 2$ & $31 \pm 4^{* *}$ & $30 \pm 3^{* *}$ \\
\hline
\end{tabular}

Data are expressed as mean \pm standard deviation $(\mathrm{SD}) ; \mathrm{n}=8 ; \mathrm{P}$ value $=$ probability of chance, $* \mathrm{P}<0.05$ and $* * \mathrm{P}<0.001$ significant difference compared with the control group while, ${ }^{\#} \mathrm{P}<0.05$ and ${ }^{\# \#} \mathrm{P}<0.001$ significant difference compared with the obese non-treated group. Sild; sildenafil.

Table 2 Serum glucose, insulin, HOMA-IR, TGs, FFA, and FGF21 and subcutaneous WAT CS activity in experimental groups

\begin{tabular}{cccc}
\hline & Control group & Obese non-treated group & Obese Sild-treated group \\
\hline Serum glucose (mg/dl) & $97 \pm 4$ & $175 \pm 14^{* *}$ & $99 \pm 5^{\# \#}$ \\
Serum insulin $(\boldsymbol{\mu I U} / \mathbf{m l})$ & $4 \pm 0.37$ & $7 \pm 0.63^{* *}$ & $4 \pm 0.4^{\# \#}$ \\
HOMA-IR & $0.97 \pm 0.1$ & $3 \pm 0.4^{* *}$ & $1.1 \pm 0.1^{\# \#}$ \\
Serum TGs (mg/dl) & $53 \pm 4$ & $134 \pm 8^{* *}$ & $51 \pm 5^{\# \#}$ \\
Serum FFA (mEq/L) & $0.68 \pm 0.13$ & $3.6 \pm 0.57^{* *}$ & $1 \pm 0.09^{\# \#}$ \\
Serum FGF21 (pg/ml) & $66 \pm 6$ & $93 \pm 7^{* *}$ & $120 \pm 9^{* * \#}$ \\
$\quad$ WAT CS activity & $258 \pm 9$ & $253 \pm 11$ & $301 \pm 13^{* * \#}$ \\
$\quad(\mathbf{n m o l} / \mathbf{m i n} / \mathbf{m g})$ & &
\end{tabular}

Data are expressed as mean \pm standard deviation $(\mathrm{SD}) ; \mathrm{n}=8 ; \mathrm{P}$ value $=$ probability of chance, $* \mathrm{P}<0.05$ and $* * \mathrm{P}<0.001$ significant difference compared with the control group while, ${ }^{\#} \mathrm{P}<0.05$ and ${ }^{\# \#} \mathrm{P}<0.001$ significant difference compared with the obese non-treated group. Sild, sildenafil; HOMA-IR, homeostatic model assessment-insulin resistance; TGs, triglycerides; FFA, free fatty acids; FGF21, fibroblast growth-21; WAT, white adipose tissue; CS, citrate synthase activity 


\section{Discussion}

The readily accessible high palatable calorie-rich foods causes energy surplus. The current mechanized society leads to energy expenditure decline. These factors and others have raised the existing pandemic of obesity and comorbid conditions of insulin resistance and Type 2 diabetes [28]. BAT is the major contributor of energy expenditure [3] and WAT is excessively expanded in obesity, thus remodeling of WAT into BAT paves the way to limit obesity and the related disorders of insulin resistance and Type 2 diabetes [10].

In our model, HFD-fed group showed significant increases in the body weight, WAT fat depots weight, adiposity index, and increased food consumption with respect to the control group that fed standard diet. Also, there were significant increases in the serum TGs, FFA, glucose, insulin, and HOMA-IR levels. These findings refer to weight gain with increased fat mass and existence of hypertriglyceridemia and insulin resistance.

Energy surplus due to increased consumption of high caloric diet causes expansion of WAT fat depots and increased adiposity index [3]. With chronic energy surplus, the accumulated fat will exceed the WAT's storage capacity leading to ectopic lipids accumulation in non-adipose organs [28]. Ectopic lipid accumulation in the liver and skeletal muscles triggers impairment of insulin signaling pathways and development of insulin resistance. Muscle insulin resistance reduces muscle glucose uptake resulting in hyperglycemia while, liver insulin resistance causes decreases in hepatic glycogen synthesis and increases in novo lipogenesis and hyperlipidemia [28]. Moreover, subsequent macrophage-induced WAT lipolysis increases fatty acid release and esterification in the liver, causing hypertriglyceridemia. All of these led to hypertriglyceridemia, hyperglycemia, and increased HOMA-IR.

Sild administration with HFD in the last 3 weeks significantly reversed the HFD-consumptionassociated changes excluding food intake that was non-significantly changed. With supporting of our data Ayala et al. [29] initially reported that Sild administration with HFD decreased body weight with recorded increase in food intake. Moreover, Behr-Roussel et al. [19] have found that chronic Sild treatment was able to restore normal levels of TGs. Thus, the improvement of the adiposityrelated parameter in spite of unchanged food intake suggests an increase in the energy expenditure.

Hypertriglyceridemia, secondary to adiposity and insulin resistance [30, 31] leads to endothelial dysfunction with disturbed endothelial NO synthase activity and NO / cGMP pathway [29]. Being cGMP is an important mediator for brown adipocytes development and differentiation [2], the PDE-5 inhibitor; Sild through its ability to conserve the cGMP could causally induce the browning process of WAT.

The UCP1, in the inner mitochondrial membrane of brown adipocytes, destroys the hydrogen gradient and releasing energy as heat instead of ATP [32]. The CS is a unique mitochondrial matrix enzyme that catalyses the first step of the Krebs cycle [4] and is considered a metabolic marker for mitochondrial oxidative capacity as well as mitochondrial integrity [33]. Subsequently, both UCP1 and augmented CS activity contribute 
to an increase in energy expenditure and were taken as markers for brown adipocytes.

The subcutaneous WAT of Sild-treated group showed significant ectopic expressions of UCP1 and CS activity increases in in comparison to the non-treated one. These outcomes denote development of brown-like adipocytes, beige/brite cells, within WAT and browning process has occurred. These beige adipocytes can arise either through development of different subpopulations or predominantly through the trans-differentiation of white adipocytes [34].

Similar findings have been previously reported in lean mice [16], prediabetic human [17], and overweight adults [18]. Thus, Sild can introduce itself as a browning agent. However, in contrary to our findings, Johann et al. [35] have published adverse metabolic effects of Sild treatment in a mice model of pre-existing obesity. Their findings revealed no changes of BAT's genes expression in the WAT and thus excluding a browning effect of Sild. This discrepancy could be attributed to differences in the duration of the experiment $(8$ days versus 3 weeks). This short duration appeared insufficient to induce beige adipocyte [36]. Additionally, differences in the route of administration (drinking water versus daily twice injection) and species as well might contribute to such effects.

Through the browning process, BAT is recruited and thus clears the blood from TGs and glucose, preventing their risky deposition in WAT, liver, and muscle and development of insulin resistance [37]. With the recent discovery of BAT's endocrinal function through synthesis and release of FGF21 [6], we supposed the physiological role of induced beige adipocytes may involve the FGF21 release. So, we assessed FGF21 levels in WAT and serum. Our data revealed that Sild treatment of obese rats led to abundant WAT's FGF21 gene expression and the highest serum FGF21 levels compared to their corresponding in the non-treated rats.

With supporting of these data, the regulatory role of PDE5-inhibitors on FGF21 has been previously demonstrated by Zhu and his colleges [38]. They found PDE5 overexpressing-cells, with subsequent decreased intracellular cGMP, were accompanied by a 20-fold decrease in FGF21 mRNA. Subsequently, the PDE5 inhibitor, Sild appears able to increase the endogenous FGF21 levels. Additionally, Stanford and colleagues [39] when transplanted BAT from donor mice into the visceral cavity of recipient mice of HFD-induced insulin resistance, have observed strong enhancement in the blood FGF21 levels with improved glucose tolerance, insulin sensitivity, and decreased body weight, as well as fat mass. This suggested the BAT's role in the FGF21 release.

Mechanistically, the metabolic homeostatic effects of FGF21 could be explained by the following; it stimulates glucose uptake in the differentiated adipocytes via induction of glucose transporter-1. Moreover, therapeutic intervention with recombinant FGF21 to obese and diabetic mice has proven to normalise blood glucose and TGs. Also, FGF21-overexpressing mice were resistant to dietinduced obesity and metabolic disturbances [40]. Furthermore, Dutchak et al. [41] have found FGF21 to act as an autocrine factor that regulates peroxisome proliferator-activated receptor $\gamma$ 
activity and glucose uptake. Additionally, FGF21 was found to regulate lipolysis in WAT [42], improve pancreatic $\beta$-cell function and survival [43], and to preserve the activity of endothelial NO synthase and subsequently the NO/cGMP pathway [44]. Quite recently, FGF21 was suggested to induce secretion of the insulin sensitising hormone, adiponectin [45, 46]. So, it is an important mediator to restore insulin sensitivity during adiposity.

In the present study, higher FGF21 serum levels were also observed in the obese non-treated rats when compared to the control group but with absence of the expected beneficial effects. It thus, corresponds to conditions of FGF21-resistance. "FGF21 resistance" refers to the increase in plasma FGF21 levels with decreased expression of the FGF21 receptor complex in WAT of obese mice [47].

FGF21 promotes metabolic homeostasis through WAT [48]; the insulin-sensitizing action of FGF21 was observed to be nullified in fatless mice and conversely, transplantation of WAT into the lipodystrophic mice restores the FGF21 responsiveness [49]. Thus, to prove obesityassociated FGF21-resistance, we assessed the subcutaneous WAT for FGF21-R1, the predominantly expressed receptor in the adipose tissue and the most responsible for FGF21metabolic effects [7].

A significant FGF21-R1 downregulation was observed in the obese non-treated rats when compared to the control group. Being WAT is an obligatory target for the metabolic actions of FGF21 through the FGF21-R1 receptors [7; 49], this receptor downregulation in obese rats blunts the metabolic effects of FGF21 and thus explaining the obesity-associated FGF21-resistant state.

With supporting of our findings, elevated serum levels of FGF21 have previously been observed in both obese insulin-resistant animals and human [25; 50; 51]. Furthermore, Tanajak et al. [52] recently reported the increased plasma FGF21 level can be used as an early biomarker for the insulin resistance and metabolic disturbances in obese insulin-resistant rats. They studied the temporal changes of FGF21 after HFD consumption and demonstrated that FGF21 levels were increased earlier than the metabolic disturbances, except for body weight and visceral fat weight gain. These data suggest that FGF21 levels are linked to the increase in body weight and visceral fat weight gain following HFD consumption [52].

The increased FGF21 levels in obesity could be attributed to a natural feedback mechanism in response to the progression of insulin resistance or induced by number of stressors including oxidative stress [53] and dietary stress as HFD with excessive fat accumulation activates the liver to synthesize FGF21 [51] the primary organ concerned with FGF21 synthesis and release [54].

Conversely, significant abundant receptor expression was observed in the Sild-treated obese rats when compared to the obese non-treated group, indicating improved responsiveness to the increased FGF21 levels and improvement of FGF21-resistant state. However, future investigations are needed to give more detailed evidence concerning these findings especially with paucity of available data. Also, further studies could be conductive to assess hepatic FGF21 
levels and to explore the possible underlying molecular mechanisms.

\section{Conclusion}

From the present data, we can conclude that Sild administration during obese condition improves adiposity and the associated insulin and FGF21resistant states. A mechanism mediated probably through Browning of the expanded WAT.

\section{Acknowledgment}

We gratefully thank the technical and administrative staff at the Medical Physiology and Biochemistry Departments, Faculty of Medicine, Benha University, for their assistance and support.

\section{Disclosure statement}

No potential conflict of interest was reported by the authors.

\section{References}

1. Jiang, S. Z., Lu, W., Zong, X. F., Ruan, H. Y., \& Liu, Y. (2016). Obesity and hypertension.Experimental and therapeutic medicine, 12(4), 2395-2399.

2. Pfeifer, A., \& Hoffmann, L. S. (2015). Brown, beige, and white: the new colour code of fat and its pharmacological implications. Annual review of pharmacology and toxicology, 55, 207-227.

3. Cannon, B., \&Nedergaard, J. A. N. (2004). Brown adipose tissue: function and physiological significance. Physiological reviews, 84(1), 277-359.

\section{Spina RJ, Chi MMY, Hopkins MG, Nemeth} PM, Lowry OH, Holloszy JO (1996) Mitochondrial enzymes increase in muscle in response to 7-10 days of cycle exercise. $\mathrm{J}$ ApplPhysiol 80:2250-2254.

5. Cypess, A. M., \& Kahn, C. R. (2010) Brown fat as a therapy for obesity and diabetes.
Current opinion in endocrinology, diabetes, and obesity, 17(2), 143.

6. Villarroya F, Cereijo R, Villarroya J, Giralt M. (2017). Brown adipose tissue as a secretory organ. Nat Rev Endocrinol.2017; 13:26-35.

7. Adams, A. C., Yang, C., Coskun, T., Cheng, C. C., Gimeno, R. E., Luo, Y., \&Kharitonenkov, A. (2013). The breadth of FGF21's metabolic actions are governed by FGFR1 in adipose tissue. Molecular metabolism, 2(1), 31-37.

8. Cheng, P., Zhang, F., Yu, L., Lin, X., He, L., Li, X., ...\& Zhang, C. (2016). Physiological and pharmacological roles of FGF21 in cardiovascular diseases.Journal of diabetes research, 2016.

9. Petrovic, N., Walden, T. B., Shabalina, I. G., Timmons, J. A., Cannon, B., \&Nedergaard, J. (2010). Chronic peroxisome proliferator-activated receptor $\gamma$ (PPAR $\gamma$ ) activation of epididymally derived white adipocyte cultures reveals a population of thermogenically competent, UCP1-containing adipocytes molecularly distinct from classic brown adipocytes. Journal of Biological Chemistry, 285(10), 7153-7164.

10. Giralt, M., \&Villarroya, F. (2013). White, brown, beige/brite: different adipose cells for different functions?.Endocrinology, 154(9), 2992-3000.

11. Aversa, A., Caprio, M., Antelmi, A., Armani, A., Brama, M., Greco, E. A., ...\&Rosano, G. M. (2011). Exposure to phosphodiesterase type 5 inhibitors stimulates aromatase expression in human 
adipocytes in vitro. The journal of sexual medicine, 8(3), 696-704.

12. Glossmann, H., Petrischor, G., \&Bartsch, G. (1999). Molecular mechanisms of the effects of sildenafil (VIAGRA®).Experimental gerontology, 34(3), 305-318.

13. El-Sakka, A. I. (2004). Efficacy of sildenafil citrate in treatment of erectile dysfunction: effect of type 2 diabetes. European urology, 46(4), 503-509.

14. Galiè, N., Ghofrani, H. A., Torbicki, A., Barst, R. J., Rubin, L. J., Badesch, D., ... \&Grimminger, F. (2005). Sildenafil citrate therapy for pulmonary arterial hypertension.New England Journal of Medicine, 353(20), 2148-2157.

15. Mitschke, M. M., Hoffmann, L. S., Gnad, T., Scholz, D., Kruithoff, K., Mayer, P., ...\&Kilić, A. (2013). Increased cGMP promotes healthy expansion and browning of white adipose tissue. The FASEB Journal, 27(4), 1621-1630.

16. Ramirez, C. E., Nian, H., Yu, C., Gamboa, J. L., Luther, J. M., Brown, N. J., \&Shibao, C. A. (2015). Treatment with sildenafil improves insulin sensitivity in prediabetes: a randomized, controlled trial. The Journal of Clinical Endocrinology \& Metabolism, 100(12), 4533-4540.

17. Li, S., Li, Y., Xiang, L., Dong, J., Liu, M., \& Xiang, G. (2018a). Sildenafil induces browning of subcutaneous white adipose tissue in overweight adults. Metabolism, 78, 106-117.

18. Francis SH, Sekhar KR, Rouse AB, Grimes KA, Corbin JD (2003). Single step isolation of sildenafil from commercially available Viagra tablets.Int $\mathrm{J}$ Impot Res 15:369-372.

19. Behr-Roussel, D., Oudot, A., Caisey, S., Coz, O. L., Gorny, D., Bernabé, J., ...\&Giuliano, F. A. (2008). Daily treatment with sildenafil reverses endothelial dysfunction and oxidative stress in an animal model of insulin resistance. European urology, 53(6), 1272-1281.

20. Babaei, P., Damirchi, A., \&Hoseini, R. (2015). The interaction effects of aerobic exercise training and vitamin $\mathrm{D}$ supplementation on plasma lipid profiles and insulin resistance in ovariectomized rats. Journal of exercise nutrition \& biochemistry, 19(3), 173.

21. Casteilla, L., Pénicaud, L., Cousin, B., \&Calise, D. (2008). Choosing an adipose tissue depot for sampling. In Adipose tissue protocols (pp. 23-38). Humana Press.

22. Taylor BA, Phillips SJ. (1996). Detection of obesity QTLs on mouse chromosomes 1 and 7 by selective DNA pooling.Genomics 1996; 34: 389-398.

23. Flier, J.S., Kahn, C.R., and Roth, J.,(1979). Receptors, anti-receptor antibodies and mechanisms of insulin resistance.The New England journal of medicine, 300 (8), 413 419.

24. Matthews, D.R., Hosker, J.P., Rudenski, A.S., Naylor, B.A., Treacher, D.F., and Turner, R.C. (1985). Homeostasis model assessment: insulin resistance and B- cell functionfrom fasting plasma glucose and insulin concentrations in man. Diabetologia. 28: 412-419. 
25. Zhang, X., Yeung, D. C., Karpisek, M., Stejskal, D., Zhou, Z. G., Liu, F., ...\&Xu, A. (2008). Serum FGF21 levels are increased in obesity and are independently associated with the metabolic syndrome in humans. Diabetes.

26. Srere PA (1969). Citrate synthase. Methods Enzymol 13:3-5.

27. Livak, K. J. and Schmittgen, T. D. (2001). Analysis of relative gene expression data using real-time quantitative PCR and the 2(Delta DeltaC(T)) Method. Methods 25, 402-408.

28. Samuel, V. T., \& Shulman, G. I. (2016). The pathogenesis of insulin resistance: integrating signalling pathways and substrate flux. The Journal of clinical investigation, 126(1), 12-22.

29. Ayala, J. E., Bracy, D. P., Julien, B. M., Rottman, J. N., Fueger, P. T., and Wasserman, D. H. (2007). Chronic treatment with sildenafil improves energy balance and insulin action in high fat-fed conscious mice. Diabetes 56, 1025-1033.

30. Subramanian, S., \&Chait, A. (2012). Hypertriglyceridemia secondary to obesity and diabetes. Biochimica et Biophysica Acta (BBA)-Molecular and Cell Biology of Lipids, 1821(5), 819-825.

31. Kusterer, K., Pohl, T., Fortmeyer, H. P., März, W., Scharnagl, H., Oldenburg, A., ...\&Busse, R. (1999). Chronic selective hypertriglyceridemia impairs endotheliumdependent vasodilatation in rats. Cardiovascular research, 42(3), 783-793.

32. Sugimoto S, Nakajima H, Kodo K, Mori J, Matsuo K, Kosaka K, et al. Miglitol increases energy expenditure by upregulating uncoupling protein 1 of brown adipose tissue and reduces obesity in dietaryinduced obese mice. Nutrition \& Metabolism 2014; 11: 14.

33. Muhammad, M. H., \& Allam, M. M. (2017). Resveratrol and/or exercise training counteract aging-associated decline of physical endurance in aged mice; targeting mitochondrial biogenesis and function. The Journal of Physiological Sciences, 1-8.

34. Okamatsu-Ogura, Y., Nio-Kobayashi, J., Nagaya, K., Tsubota, A., \& Kimura, K. (2017). Brown adipocytes postnatally arise through both differentiation from progenitors and conversion from white adipocytes in Syrian hamster. Journal of Applied Physiology.

35. Johann, K., Reis, M. C., Harder, L., Herrmann, B., Gachkar, S., Mittag, J., \&Oelkrug, R. (2018). Effects of sildenafil treatment on thermogenesis and glucose homeostasis in diet-induced obese mice.Nutrition \& diabetes, 8(1), 9.

36. Warner, A., \&Mittag, J. (2016). Breaking BAT: can browning create a better white?.Journal of Endocrinology, 228(1), R19-R29.

37. Srivastava, S., \&Veech, R. L. (2019). Brown and brite: The fat soldiers in the anti-obesity fight. Frontiers in Physiology, 10, 38.

38. Zhu, B., Xu, Y. C., \& Stevens, T. (2009). FGF21 determined angiogenic phenotypes in pulmonary endothelial cells. The FASEB Journal, 23(1 Supplement), 965-3.

39. Stanford, K. I., Middelbeek, R. J., Townsend, K. L., An, D., Nygaard, E. B., 
Hitchcox, K. M., ...\& Goodyear, L. J. (2012). Brown adipose tissue regulates glucose homeostasis and insulin sensitivity. The Journal of clinical investigation, 123(1).

40. Kharitonenkov, A., Shiyanova, T. L., Koester, A., Ford, A. M., Micanovic, R., Galbreath, E. J., ...\&Gromada, J. (2005). FGF-21 as a novel metabolic regulator.The Journal of clinical investigation, 115(6), 1627-1635.

41.Dutchak PA, Katafuchi T, Bookout AL, Choi JH, Yu RT, Mangelsdorf DJ, Kliewer SA. (2012). Fibroblast growth factor-21 regulates PPARgamma activity and the antidiabetic actions of thiazolidinediones. Cell 2012;148:556-567.

42. Hotta Y, Nakamura H, Konishi M, Murata $\mathbf{Y}$, Takagi $\mathrm{H}$, Matsumura $\mathrm{S}$, Inoue $\mathrm{K}$, Fushiki T, Itoh N (2009). Fibroblast growth factor 21 regulates lipolysis in white adipose tissue but is not required for ketogenesis and triglyceride clearance in liver. Endocrinology 2009;150:4625-4633.

43. Bookout, A. L., De Groot, M. H., Owen, B. M., Lee, S., Gautron, L., Lawrence, H. L., ...\&Kliewer, S. A. (2013). FGF21 regulates metabolism and circadian behavior by acting on the nervous system. Nature medicine, 19(9), 1147.

44. Wang, X. M., Song, S. S., Xiao, H., Gao, P., Li, X. J., \& Si, L. Y. (2014). Fibroblast growth factor 21 protects against high glucose induced cellular damage and dysfunction of endothelial nitric-oxide synthase in endothelial cells. Cellular physiology and biochemistry, 34(3), 658671.

45. Hui, X., Feng, T., Liu, Q., Gao, Y., \&Xu, A. (2016). The FGF21-adiponectin axis in controlling energy and vascular homeostasis.Journal of molecular cell biology, 8(2), 110-119.

46. Li, H., Wu, G., Fang, Q., Zhang, M., Hui, X., Sheng, B., ...\&Jia, W. (2018b). Fibroblast growth factor 21 increases insulin sensitivity through specific expansion of subcutaneous fat. Nature communications, 9(1), 272.

47. Hale, C., Chen, M. M., Stanislaus, S., Chinookoswong, N., Hager, T., Wang, M., ...\&Xu, J. (2012). Lack of overt FGF21 resistance in two mouse models of obesity and insulin resistance.Endocrinology, 153(1), 69-80.

48. Véniant, M. M., Hale, C., Helmering, J., Chen, M. M., Stanislaus, S., Busby, J., ...\& Lloyd, D. J. (2012). FGF21 promotes metabolic homeostasis via white adipose and leptin in mice. PloS one, 7(7), e40164.

49. Chui, P. C., Antonellis, P. J., Bina, H. A., Kharitonenkov, A., Flier, J. S., \&Maratos-Flier, E. (2010). Obesity is a fibroblast growth factor 21 (FGF21)resistant state. Diabetes, 59(11), 2781-2789.

50. Benomar, Y., Amine, H., Crépin, D., Al Rifai, S., Riffault, L., Gertler, A., \&Taouis, M. (2016). Central Resistin/TLR4 impairs adiponectin signaling contributing to insulin and FGF21 resistance. Diabetes, db151029.

51. Quesada-López, T., Cereijo, R., Turatsinze, J. V., Planavila, A., Cairó, M., Gavaldà- 
Navarro, A., ... \&amp; Eizirik, D. L. (2016).The lipid sensor GPR120 promotes brown fat activation and FGF21 release from adipocytes. Nature communications, 7 , 13479.

52. Tanajak, P., Pongkan, W., Chattipakorn, S. C., \&Chattipakorn, N. (2018). Increased plasma FGF21 level as an early biomarker for insulin resistance and metabolic disturbance in obese insulin-resistant rats. Diabetes and Vascular Disease Research, 15(3), 263-269.

53. Gómez-Sámano, M. Á., Grajales-Gómez, M., Zuarth-Vázquez, J. M., NavarroFlores, M. F., Martínez-Saavedra, M., Juárez-León, Ó. A., ...\& Cuevas-Ramos, D. (2017). Fibroblast growth factor 21 and its novel association with oxidative stress.Redox biology, 11, 335-341.

54. Nishimura, T., Nakatake, Y., Konishi, M., \&Itoh, N. (2000). Identification of a novel FGF, FGF-21, preferentially expressed in the liver.BiochimicaetBiophysicaActa (BBA)-Gene Structure and Expression, 1492(1), 203-206. 